\title{
REABILITAÇÃO DA ESTAÇÃO FERROVIÁRIA DE ÁLVARES MACHADO / SP
}

\author{
Mariane Garcia, Fabrícia Dias da Cunha de Moraes Fernandes Borges \\ Universidade do Oeste Paulista - UNOESTE. Faculdade de Engenharias e Arquitetura e Urbanismo, Presidente \\ Prudente-SP. Email: Mariane garcia@hotmail.com
}

\section{RESUMO}

A presente dissertação aborda temas relacionados a história das linhas férreas no Brasil, estreitando ao estado de São Paulo e mais precisamente na região do oeste paulista, bem como a importância das linhas férreas na configuração urbana e social das cidades do interior de São Paulo. A monografia aponta também a história do surgimento do município de Álvares Machado graças à chegada da estrada de ferro Alta Sorocabana, enfatiza e destaca a preservação de patrimônios culturais a fim de resgatar a história e preservar a memoria social coletiva, além de relatar a influência e a necessidade de cultura e de espaços culturais nas sociedades contemporâneas. O propósito do presente estudo é articular edificações de natureza histórica com processos de restauração e reutilização, dando subsídios para o desenvolvimento de um projeto de arquitetura e urbanismo composto por um centro cultural e um espaço de área verde destinados ao público, onde haja vivência e trocas de experiências entre diferentes categorias de usuários.

Palavras - chave: Estação Ferroviária, Linha Férrea, Álvares Machado, Restauro, Cultura.

\section{REHABILITATION OF THE RAILWAY STATION ALVARES MACHADO / SP}

\begin{abstract}
This dissertation addresses issues related to the history of railroads in Brazil, strengthening the state of São Paulo and more precisely in the west of São Paulo region, and the importance of railways in the urban and social setting of the cities of São Paulo. The paper also points out the history of the emergence of Álvares Machado municipality thanks to the arrival of the High Sorocabana railroad, emphasizes and highlights the preservation of cultural heritage in order to rescue the history and preserve the collective social memory, in addition to reporting the influence and the need for culture and cultural spaces in contemporary societies. The purpose of this study is to articulate historical in nature buildings with restoration processes and reuse, providing subsidies for the development of an architectural design and urban planning consists of a cultural center and a green space area to the public, where there is experience and exchanges experiences among different categories of users.
\end{abstract}




\section{INTRODUÇÃO}

Para Rodrigues (2006) o cenário mundial está sofrendo transformações devido à globalização - fenômeno resultante das interações entre fatores sociais, econômicos e culturais. Se por um lado a globalização representa a interconexão entre capital e mercado, indivíduos e diferentes regiões; por outro ela retrata a anulação de culturas e a perda das identidades ao aproximar diferentes grupos religiosos, étnicos e culturais. A identidade por sua vez, é um processo que se desencadeia da interação entre trocas reais e simbólicas no meio de diferentes indivíduos; caracterizando-se em um sentimento de pertencimento construído por intermédio de vivencias e lembranças do passado de uma determinada sociedade. O homem em geral necessita de estruturas de classificação e referenciação para sua ação e pensamento, assim como necessita de identidade para se diferir dos demais indivíduos e se caracterizar como pessoa ou como grupo social. Desta forma, a identidade cultural atua como elemento estruturador e definidor, no qual se reporta ao sentimento construído pelo próprio indivíduo através de sua vivência, memória e de seu pertencimento a uma cultura, seja ela nacional ou local (PATRIOTA, 2002).

Para Castriota (2009) a palavra patrimônio é originária do romano antigo e significa "herança do pai", já o termo monumento tem sua origem do latim Monere advertindo aos verbetes: "lembrar, memorar". Deste modo o patrimônio histórico, artístico e cultural, junto aos monumentos, é dito como o conjunto de bens que relatam e possibilitam a compreensão da identidade histórica e social, além de manter vivos os costumes de uma sociedade pendurando-os de geração em geração. Assim a concepção de "lugar" e de "memória" estão associadas, pois, através da preservação do lugar obtém-se a continuidade temporal e, portanto, a memória social viva. Até o final da década de 1970 o patrimônio tinha caráter político - elitista, isto é, apenas uma minoria pecuniosa detinha o poder sobre as decisões a respeito dele; contudo, a partir de 1980 as demais classes sociais e diferentes etnias passaram a ser também contempladas. No século XX, 0 Brasil passa por uma crise de valores estéticos tradicionais no âmbito arquitetônico e artístico, além da expansão da população e o crescimento substancial da malha urbana. É neste contexto, em que novos materiais industrializados como, por exemplo, o metal e o vidro, são empregados visando à rapidez e racionalização das obras. A arquitetura de ferro no cenário nacional ganha destaque nos edifícios ferroviários, considerados testemunhos históricos do esforço do transporte do principal produto de exportação no país: o café. Deste modo, as estradas de ferro - estimadas como símbolo da industrialização no país, foram agentes de caracterização de diversas regiões brasileiras, além alavancarem transformações nas cidades, influenciando tanto na configuração urbana como na configuração social. No entanto, por volta de 1920, com a mudança radical no meio de transporte brasileiro (do ferroviário para o rodoviário dito mais "rápido e eficaz"), um vasto número de linhas foi desativado e edificações abandonadas. Visto que o cenário urbano contemporâneo se propende cada vez mais à homogeneização através do esquecimento de diferenças regionais e da autenticidade, devido aos processos de massificação; o governo e os cidadãos juntos devem se conscientizar e contribuir para que as cidades evoluam de maneira equilibrada através da integração entre políticas de preservação e políticas urbanas; preservando o patrimônio histórico local por intermédio de reaproveitamento e a readaptação destes antigos edifícios ferroviários tornando - as oficinas, depósitos, ateliês, museus, galerias de arte, centros de estudos urbanos, entre outros diversos usos (KÜHL,1998).

Desta forma, o interesse surgiu mediante ao abandono da Estação Ferroviária do município de Álvares Machado junto à carência e falta de inserção de cultura e espaços dedicados a tais atividades no cotidiano da comunidade machadense. A finalidade principal deste projeto é estudar por meio de autores os quais tem se dedicado ao tema, a relevância das estradas de ferro bem como suas edificações estabelecidas para armazenagem, depósitos e oficinas de produtos, na configuração da malha urbana das cidades brasileiras; refletir sobre a necessidade da preservação de patrimônios históricos; planear a respeito da globalização e sua consequente massificação que 
tem caracterizado a perda de identidade cultural e referenciais de diversos grupos sociais; e por fim mas não menos importante, inserir na cidade de Álvares Machado um espaço multiuso o qual tenha por objetivo reunir um público com características diversificadas, além de promover atividades heterogêneas e multidisciplinares, explorando as potencialidades presentes no espaço através de uma arquitetura mais simplória que resgate e preserve as características originais do edifício pré existente. $O$ projeto consiste no restauro e readequação do espaço físico, além de promover um novo uso para a atual Estação Ferroviária de Álvares Machado, proporcionando assim a integração do espaço que hoje encontra - se obsoleto, degradado e abandonado, com o seu entorno.

O objetivo geral respalda-se em fazer um estudo sobre a influência da ferrovia na configuração da malha urbana e propor a revitalização do espaço da Estação Ferroviária de Álvares Machado a fim de promover o uso para um centro cultural. Já os objetivos específicos são:

- Promover um centro cultural que atenda às necessidades da população presente nos bairros próximos à estação;

- Promover atividades heterogêneas e multidisciplinares;

- Explorar as potencialidades presentes no espaço;

- Restaurar as características originais do edifício;

- Projetar novos blocos e espaços a fim de atender os novos usos dados ao local;

\section{MEMORIAL DE CONCEITO E PARTIDO ARQUITETÔNICO}

O conceito do projeto baseia-se na preservação e salvaguarda da estação ferroviária e galpão de armazenagem, isto é, edificações de caráter histórico; juntamente à promoção da cultura, educação e lazer a população machadense através de um projeto intitulado de "Estação do Conhecimento". A intenção é possibilitar um amplo espaço de convivência em uma área que atualmente encontra-se abandonada e em situação de descaso público, a partir da estimulação e integração da arte e da cultura entre a população de Álvares Machado. A proposta estabelece ainda a apropriação do espaço de forma convidativa e participativa determinando planos e eixos visuais de ampla permeabilidade, bem como a relação da obra e sua integração com o entorno através do uso de formas simples as quais transmitam a sensação de leveza, e por fim o conceito de "museu fora da caixa" por meio da criação de espaços livres, dinâmico, flexíveis e abertos onde possão ser desenvolvidas atividades interativas e em grupo.

Os princípios estruturantes do partido arquitetônico da proposta são: a horizontalidade de forma a produzir uma arquitetura de baixo impacto visual sobre o entorno e que dialogue com as demais edificações através do mesmo gabarito de altura; a setorização através de blocos, organizando os três setores principais: setor expositivo, setor administrativo e setor cultural; e o conforto ambiental por meio da utilização de estratégias adequadas ao clima local garantindo uma edificação com conforto e desempenho térmico e acústico. Além disso, será empregado o processo de restauração e reabilitação das pré-existências, por meio da manutenção das características arquitetônicas históricas tanto da estação quanto do galpão de armazenagem, bem como a adequação aos novos usos que o edifício irá receber, através de sistemas de fechamento, aberturas e estruturação de espaços flexíveis através do drywall.

\section{MEMORIAL DESCRITIVO DO PROJETO}

A Estação Ferroviária de Álvares Machado é considerada o ponto inicial do surgimento e da colonização do município. Localizada em um dos principais acessos da cidade, isto é, na Estrada Artur Boigues Filho, a via ainda interliga Álvares Machado ao maior município do pontal do Paranapanema: Presidente Prudente. O local foi escolhido, pois atuou como agente caracterizador da urbanização do município; está localizado em um ponto estratégico da cidade e carrega em si características arquitetônicas de um determinado período histórico. Além de que 
através da edificação é possível compreender como se originou Álvares Machado (graças ao ciclo do café e a chegada da linha férrea na região). O prédio também contém em si elementos simbólicos que representam e contam a história da cidade e a memória de sua população. A ideia inicial consiste em espaços dispostos de maneira funcional e racional, onde haja uma relação dinâmica e flexível, com a utilização de materiais e tecnologias construtivas adequadas à realidade do local e dentro do contexto cultural. Além do mais, o fato de existir no local duas pré-existências junto às características topográficas do terreno, contribuíram para traçar as diretrizes projetuais e organizativas do projeto. $O$ desenho ou mais precisamente a implantação do centro cultural foi concebida com simplicidade, valorizando - se, sobretudo seu entorno (os bairros mais segregados da cidade) e as pré-existências (estação ferroviária e armazém), assim como no caso dos projetos já mencionados como referencias projetuais, a historicidade do sítio contribuiu para a concepção da obra como um referencial na paisagem urbana local. O lote delimitado como espaço de intervenção possui uma área total de 13.226,099 $\mathrm{m}^{2}$. O projeto foi desenvolvido com acessos através da via Presidente Prudente e estrada Arthur Boigues Filho considerando-se a potencialidade de ambas, totalizando uma área construída de 1.195,09 $\mathrm{m}^{2}$.

O passeio se inicia através do museu, locado no edifício da antiga estação ferroviária, utilizado como área de exposição permanente onde serão apresentadas em ordem cronológica e de maneira didática e interativa a trajetória histórica da cidade, sua formação e fundação em função da ferrovia. No museu o acesso acontece através do foyer integrando as demais salas de exposições; a circulação horizontal do prédio acontece tanto internamente quanto externamente, isto é, por meio da antiga plataforma utilizada como embarque e desembarque de passageiros, que além de atuar como circulação também abriga um pátio de convivência e deck de contemplação cobertos. O acervo a ser utilizado será misto, composto por fotografias, maquetes, objetos, pinturas, bem como painéis virtuais, mesas touchscreen, totens áudio visuais e jogos interativos. $O$ edifício conta também com a presença de uma sala de reserva técnica, sala para manutenção, depósito de materiais de limpeza e a presença de uma loja de guloseimas e cafeteria dentro de uma antiga locomotiva adaptada e estacionada paralelamente a plataforma de embarque possibilitando aos visitantes a compra de doces típicos da região. Os materiais de revestimento bem como os acabamentos originais do interior do edifício foram mantidos evitando assim sua descaracterização, devido à historicidade do prédio, e também em respeito à memória.

O antigo galpão abrigará o setor administrativo com salas de oficinas e área expositiva dos produtos ali produzidos em aulas. Devido às características tipologicas dos galpões e ao seu uso inicial, isto é, de estocagem para produtos e maquinários destinados as locomotivas, o prédio inicialmente não conta com paredes internas, seu pé direito apresenta 5,50 metros e suas janelas estão locadas em um peitoril de 4,00 metros. Desta forma para atender as novas necessidades foi preciso realizar as divisões internas necessárias através da utilização do drywall graças as suas vantagens, além da construção de novas esquadrias tanto portas quanto janelas que segundo Montenegro (1931) a presença das portas facilita a entrada de ar e sua circulação cruzada através das janelas utilizadas como saída de ar no mesmo nível do forro, evitando assim a formação de camada de ar quente viciado e sem saída. Além da ventilação cruzada o anexo conta em seu interior com a presença de um pequeno curso d'água com profundidade de $20 \mathrm{~cm}$ e largura máxima de $50 \mathrm{~cm}$ em determinados trechos, a intenção é utilizar o elemento água como contribuinte para o conforto térmico do espaço. Os revestimentos das paredes com exceção das áreas molhadas, isto é banheiros, copa dos funcionários, depósito de materiais entre outros, receberão no piso porcelanato de cimento queimado. As paredes internas de alvenaria serão revestidas com porcelanato com textura semelhante á pedra natural. Nas salas de oficinas o isolamento e controle de acesso do espaço acontecem por meio de painéis deslizantes (com medidas variáveis de 1,50 metros ou 2,50 metros de largura) que quando fechados atuam como expositores possibilitando aos visitantes enxergar a linha do tempo e a história do município. 
O novo anexo contém em seu programa de necessidades um "espaço digital", ou seja, uma sala destinada à navegação de internet, estudos, pesquisa e biblioteca, no qual seus fechamentos laterais acontecem através de painéis corrediços deslizantes compostos por blocos de vidros opacos, translúcidos e ora vazados, proporcionando desta forma maior iluminação e ventilação ao ambiente. Outro aspecto importante deste mesmo ambiente foi à criação de estantes para livros pivotantes - como o caso do antecedente projetual Livraria da Vila as quais possibilitam tanto o isolamento quanto a integração dos ambientes. O volume principal do prédio encontra-se inserido dentro de empenas de aço corten trabalhadas em elementos vazados criando uma circulação horizontal externa e o prédio comporta em seu eixo central um pátio interno descoberto destinado à leitura, convivência e contemplação.

Devido as especificidades, a sala de auditório, teatro e cinema necessitam de estudos isolados das demais áreas do edifício. Buscando um melhor desempenho acústico e evitando a reverberação dos sons. Deste modo, as paredes da sala não são paralelas e internamente são revestidas de materiais rugosos para melhor absorver o som, como revestimento de piso foi utilizado a madeira, pois é antiderrapante, possui altos índices de resistência mecânica, e ainda diminui o impacto. No forro por sua vez será utilizado o forro acústico speedry.

Além dos três anexos o complexo cultural conta ainda com a presença de diretrizes para a futura construção de um parque linear em todo o contorno da linha férrea, evitando-se assim trabalhar apenas com os edifícios isolados, mas sim envolvendo todo seu entorno como meio de integração dos espaços e evitando vazios urbanos, bem como pontos de abandono geradores de conflitos e violência. Toda a extensão do parque e consequentemente do complexo não apresenta limites verticais como muros, alambrados, gradis, muretas etc, proporcionando a relação direta entre o público e o privado e ainda contemplando ao usuário a livre circulação pelo espaço. $O$ projeto do parque compreende três áreas distintas: a primeira destinada aos brinquedos infantis, a segunda contempla o teatro de arena e por fim a terceira área a qual engloba o bicicletário.

\section{CONCLUSÃO}

A proposta de criação de um centro cultural na cidade de Álvares Machado traz átona e salienta a discussão a respeito de edifícios destinados a arte e cultura. Construir um centro cultural na área da antiga estação ferroviária busca resgatar os valores históricos da edificação, preservar a memória coletiva, oferecer á população um ambiente que possa ser compartilhado coletivamente independentemente do gênero ou idade, assim possibilitando a agregação de diversas classes sociais e ainda, beneficiar a sua zona de inserção.

O trabalho de conclusão de curso abordou por meio de um panorama breve e geral o histórico das linhas férreas, bem como suas edificações adjacentes.

\section{REFERENCIAS}

BRANDI, C. Teoria da restauração. Coleção Cantos do Rio, 3a edição, São Paulo, Ateliê Editorial, 2008. Local: Unidade III

BRASIL. Constituição (1988). Constituição da Republica Federativa do Brasil. Brasília, DF: Senado Federal: Centro Gráfico, 1988. 292p. Disponível em:< http://www.planalto.gov.br/ccivil 03/Constituicao/Constituicao.htm> Acesso em: 24 set. 2015.

CASTRIOTA, L. Patrimônio cultural: conceitos, políticas, instrumentos. 1 ed. São Paulo: Annablume, 2009. Local: Unidade III

KÜHL, B. Arquitetura do Ferro e Arquitetura Ferroviária em São Paulo: reflexões sobre a sua preservação. São Paulo: Ateliê Editorial, 1998. Local: Unidade III 
PATRIOTA, L.M. Cultura, identidade cultural e globalização. 2002. 06f. Dissertação (Mestrado) Universidade Estadual do Paraíba, João Pessoa - PB. 